\title{
Cross-cultural adaption of the German Quebec Back Pain Disability Scale: an exposure-specific measurement for back pain patients
}

This article was published in the following Dove Press journal:

Journal of Pain Research

II January 2016

Number of times this article has been viewed

\author{
Jenny Riecke' \\ Sebastian Holzapfel' \\ Winfried Rief' \\ Harald Lachnit ${ }^{2}$ \\ Julia A Glombiewski' \\ 'Department for Clinical Psychology \\ and Psychotherapy, ${ }^{2}$ Department for \\ Associative Learning, University of \\ Marburg, Marburg, Germany
}

Study design: Cross-cultural translation and psychometric testing.

Objective: The purpose of the present study was to examine reliability and validity of a crosscultural adaption of the German Quebec Back Pain Disability Scale (QBPDS) in a context of a randomized controlled trial evaluating the effectiveness of graded in vivo exposure in chronic low back pain patients.

Background: The QBPDS is one of the most widely used disease-specific disability questionnaires. In particular, for cognitive behavioral treatments with a clear focus on behavioral aspects such as graded in vivo exposure, the QBPDS provides an ascertained strategy with a sound conceptual basis and excellent quality criteria. Nevertheless, there is conflicting evidence concerning factor structure and a German adaption is missing.

Methods: The cross-cultural adaption followed international guidelines. Psychometric testing was performed using data from 180 participants with chronic low back pain. The psychometric analyses included internal consistency, convergent, and divergent validity. Exploratory factor analysis was used to determine the underlying factor structure.

Results: The QBPDS showed strong psychometric properties, with high internal consistency for the full scale $(\alpha=0.94)$ and good convergent and divergent validity. The factor analysis revealed a four-factor solution (bending, ambulation, brief effortful movements, and longlasting postures).

Conclusion: The translation and cross-cultural adaption of the QBPDS into German was successful. The German version proved to be a valid and reliable instrument and is well suited for use in the context of an exposure-based psychological treatment.

Keywords: Chronic pain, back pain, questionnaire, functional disability, German, validation

\section{Introduction}

The Quebec Back Pain Disability Scale (QBPDS) ranks among the most widely used and accepted disease-specific functional disability scales. In contrast to other disability instruments, the QBPDS measures functional disability solely in terms of activity limitations making it suitable for psychological treatments with a clear focus on behavioral aspects. A cognitive behavioral treatment that explicitly includes the confrontation and performance of avoided movements is graded in vivo exposure. ${ }^{1}$ The QBPDS provides clinicians with important information about which domains of activities are affected by pain and which can be practiced during therapy. Furthermore, the scale is recommended as an outcome measure both to evaluate treatment success and to monitor treatment progress. ${ }^{2}$

The Initiative on Methods, Measurement, and Pain Assessment in Clinical Trials guidelines states that physical functioning is one of the core outcomes that should
Correspondence: Julia A Glombiewski artment for Clinical Psychology and Psychotherapy, University of Marburg, Gutenbergstraße 18, 35032 Marburg, Germany Tel +4964212823617

Fax +49642128 28904 Email jg@staff.uni-marburg.de (c) (i) (-) 2016 Riecke et al. This work is published by Dove Medical Press Limited, and licensed under Creative Commons Attribution - Non Commercial (unported, v3.0) BY LC License. The full terms of the License are available at http://creativecommons.org/licenses/by-nc/3.0/. Non-commercial uses of the work are permitted without any further pew to how to request permission may be found at: http://www.dovepress.com/permissions.php 
be assessed with functional disability scales. ${ }^{3}$ Cross-cultural adaptations of international used back pain-related questionnaires are urgently needed and the administration of standardized questionnaires, rather than the creation of new scales, is strongly recommended. ${ }^{4}$ Existing generic measures include the Pain Disability Index (PDI), which is one of the most frequently used instruments measuring disability associated with pain in different areas of life. ${ }^{5}$ Popular diseasespecific functional disability scales are the Roland-Morris Disability Questionnaire (RMDQ), the Oswestry Disability Index, and the QBPDS. ${ }^{6,7}$ Since its development, an increasing number of studies demonstrated the good psychometric properties of the QBPDS and recommended the scale also for the use in research. ${ }^{8}$ The scale revealed high internal consistencies and showed excellent reliability with intraclass correlation coefficient (ICC) $>0.9 .^{9-14}$

The QBPDS was developed based on a sound conceptual model. The original authors constructed the items using the World Health Organization's definition of disability, which defines disability as "any restriction or lack to perform an activity". ${ }^{15}$ Extensive preliminary studies with both clinical interviews and statistical methods ensured a good item selection and item reduction procedure and overall leaded to the development of a well-established questionnaire with good content validity. ${ }^{16}$

Nevertheless, conflicting evidence exists regarding the factor structure of the QBPDS. To date only two studies performed factor analysis. ${ }^{17,18}$ The original study by Kopec et al and a Greek research group found support for a sixfactor solution while the results of a more recent study suggest a four-factor solution. ${ }^{2,17,18}$ The analysis of underlying factors provides clinicians with information about specific subscales that can be used for individually tailored therapy. If a patient scores high in a specific subscale, the treatment can be adapted to improve the functioning in this particular domain of activity.

The QBPDS has been adapted to various languages all over the world, among others Dutch, Turkish, Brazilian, Greek, Arabic, Chinese, and Hungarian languages, allowing an international comparison of study results. However, no official German translation of the QBPDS is available. ${ }^{9,11-14,17,18}$ We developed a German version of the QBPDS considering international guidelines of cross-cultural adaption to follow the call for more national versions of back pain-related disability questionnaires. ${ }^{19}$ The purpose of the present study was to assess the psychometric properties of the German adaption of the QBPDS and to provide further data concerning the factor structure.

\section{Methods Data collection}

A total of 180 persons with chronic back pain (defined as back pain that has persisted 3 months or more) and German mother tongue were recruited via the Internet. The survey was promoted on websites of several patient organizations and support groups for chronic pain patients in Germany as well as in an inpatient rehabilitation center (MediClin Klinik am Hahnberg, Germany). All participants provided informed consent to participate, and the study was approved by the Ethics Committee of the Department of Psychology, Philipps-University Marburg, Marburg, Germany.

\section{Translation and cross-cultural adaption}

The translation and cross-cultural adaption process followed the guidelines of Beaton et al. ${ }^{19}$ First, two forward translations from English into German were performed. Next, these translations were compared with one another and with the original English version. One native English speaker with German as a second language who was blind to the original version carried out a back-translation of the first German version into English. An expert committee compared the back-translated version with the original English version and created a pre-final version.

The pre-final version was administered to a group of five patients suffering from chronic back pain. The patients provided general remarks about the questionnaire and were interviewed about potential difficulties in understanding the items. The pre-final German version and the back-translated version of the questionnaire were also sent to the original author of the QBPDS, who approved the changes that had been made. In particular, modifications were made due to cultural and linguistic factors: "Walk a few blocks (300-400 m)" was changed to "Walk in the neighborhood", "Walk several miles" was changed to "Walk several kilometers", "Reach up to high shelves" was changed to "Take something from a high shelf", and "Run one block" was changed to "Run in the neighborhood". Because refrigerators in Germany tend to be placed much higher than refrigerators in Canada, we changed the item "Take food out of the refrigerator" to "Take something out of a floor cupboard".

\section{Measures}

The QBPDS measures functional disability related to basic daily activities, which can be classified into six domains: bed/ rest, sitting/standing, ambulation, movement, bending/stooping, and handling of heavy objects. ${ }^{15}$ Patients are asked to answer the QBPDS based on the difficulty of performing the 
activities on the current day. The 20 items are answered on a 6-point numerical rating scale indicating the level of difficulty (0, "not difficult at all"; 1 , "minimally difficult"; 2 , "somewhat difficult"; 3, "fairly difficult"; 4, "very difficult"; and 5, "unable to do"). The total score is the sum of all the items, and ranges from 0 to 100 points. Participants were asked to complete a questionnaire battery that contained the QBPDS and two additional functional status questionnaires, the RMDQ and the PDI, to assess convergent validity. The Tampa Scale of Kinesiophobia and the Pain Catastrophizing Scale were also included to allow analysis of divergent validity. ${ }^{20-23}$ Average pain intensity over the last 4 weeks was rated on an 11-point numeric rating scale ( 0 , no pain; 10 , pain at its worst).

\section{Statistical analysis}

Floor and ceiling effects were analyzed by calculating the number of individuals obtaining the lowest $(0)$ or the highest (100) possible QBPDS scores. In addition, these effects were examined by computing the proportion of individuals at each end of the scale who obtained a score within the limits of the minimal detectable change at the $95 \%$ confidence level $\left(\mathrm{MDC}_{95 \%}\right)$.

Exploratory factor analysis was conducted to estimate the underlying factors. The factor rotation procedure was direct oblimin due to the possibility of extracted factors being correlated. The Kaiser-Meyer-Olkin measure and Bartlett's test of sphericity were used to test the appropriateness of factor analysis. Several criteria were used to determine the number of factors. We considered the scree plot and the Kaiser criterion, which specifies that factors must have eigenvalues greater than one. Furthermore, a Minimal Average Partial Test was conducted to provide a more reliable method, which is based on statistical principles. ${ }^{24}$ The procedure includes a complete principal component analysis and the examination of a series of matrices of partial correlations. Components are retained as long as the variance represents systematic than unsystematic variance. In this characteristic, the evaluation is very close to the actual goal of factor analysis itself, which makes it a convenient method in this context.

Internal consistency was assessed with Cronbach's $\alpha$, which is based on the average correlations of items within a test. ${ }^{25}$ Values between 0.7 and 0.95 are considered to indicate good internal consistency. ${ }^{26}$

Construct validity was analyzed using Pearson correlation coefficients, following the criteria recommended by Fisseni. ${ }^{27}$ To demonstrate high convergent validity, the QBPDS should show high positive correlations $(r \geq 0.6)$ with other question- naires measuring disability (RMDQ and PDI). To fulfill criteria for divergent validity, the QBPDS should show low positive correlations $(r \leq 0.4)$ with pain intensity, pain catastrophizing, fear of movement, and emotional distress.

All statistical analyses were conducted using the Statistical Package for Social Sciences (SPSS version 19; IBM Corporation, Armonk, NY, USA); $P$-values $<0.05$ were considered significant.

\section{Results Study sample}

The analyses of construct validity, internal consistency, and factor structure were conducted using data from 180 participants (online + inpatient sample). Table 1 shows descriptive statistics for the samples. The study sample is comparable to other chronic low back pain populations with respect to the distribution of men and women, the spread of age, duration of pain, degree of impairment, and pain intensity. ${ }^{28,29}$

\section{Missing data and normality of score distribution}

For the full QBPDS scale, $0.33 \%$ of the data were missing. Missing data for individual items ranged from zero to three missing values per item. The Kolmogorov-Smirnov test indicated that all items were nonnormally distributed (all $P$-values $<0.05)$. However, no items exceeded the critical values for skewness $(>7)$ or kurtosis $(>2)$. No participant obtained the minimum (0) or maximum (100) possible scores. The proportion of scores lying within the range of the $\mathrm{MDC}_{95 \%}$ at the two ends of the scale was $1.1 \%$.

\section{Factor structure}

Bartlett's test of sphericity was significant $\left(\chi^{2}=2,123.88\right.$, $d f=190, P<0.001)$, and the value of Kaiser-Meyer-Olkin

Table I Sample characteristics

\begin{tabular}{lll}
\hline Measures & $\begin{array}{l}\text { Online sample } \\
(\mathbf{n}=\text { I 05) } \mathbf{M}(\mathbf{S D})\end{array}$ & $\begin{array}{l}\text { Inpatient sample } \\
(\mathbf{n}=75) \mathbf{M}(\mathbf{S D})\end{array}$ \\
\hline Age (years) & $49.82(1 \mathrm{I} .62)$ & $53.31(7.49)$ \\
Sex, female/male (\%) & $73.3 / 26.7$ & $66.7 / 33.7$ \\
Pain intensity (0-10) & $5.94(2.08)$ & $4.88(1.93)$ \\
QBPDS & $49.76(17.58)$ & $43.58(18.08)$ \\
PDI & $40.52(12.63)$ & $25.55(12.82)$ \\
TSK & $38.56(6.52)$ & $39.14(6.58)$ \\
RMDQ & $14.25(4.76)$ & $12.88(6.2)$ \\
\hline
\end{tabular}

Abbreviations: M, mean; PDI, Pain Disability Index; QBPDS, Quebec Back Pain Disability Scale; RMDQ, Roland-Morris Disability Questionnaire; SD, standard deviation; TSK, Tampa Scale of Kinesiophobia. 
measure of sampling adequacy was 0.92. Therefore, the data were considered appropriate to use for factor analysis.

Principal axis factoring revealed a four-factor solution, with eigenvalues between 9.16 and 1.01 accounting for $57.43 \%$ of the total variance. The communalities of the items ranged from 0.34 to 0.95 (mean $=0.57$; see Table 2).

Both the Kaiser criterion and the scree plot supported a four-factor solution. However, the Minimal Average Partial Test revealed three factors. Statistical criteria are a very good orientation but finally components should be good in respect of content and clinical meaningfulness. After taking into consideration the results from each method as well as theoretical considerations, we decided on a four-factor solution.

The first factor includes everyday activities involving bending. The second factor includes moving and walking. The third factor involves brief effortful activities, such as lifting, carrying, reaching, overhead movements, pushing, or pulling objects. The fourth factor includes the three main postures (sitting, standing, and lying in bed), and these items imply longer time periods.
Accordingly, we labeled the factors as follows: bending (F1), ambulation (F2), brief effortful movements (F3), and long-lasting postures (F4).

\section{Internal consistency}

Internal consistency was excellent, with Cronbach's $\alpha=0.94$ for the full scale. The item-total correlations ranged from 0.46 to 0.74 . The four subscales also showed good internal consistency, with Cronbach's $\alpha$ values of 0.90 (bending), 0.82 (ambulation), 0.87 (brief effortful movements), and 0.76 (long-lasting postures).

\section{Construct validity: QBPDS and other parameters at baseline}

The QBPDS showed a high positive correlation $(r=0.78)$ with the PDI and a moderate correlation $(r=0.54)$ with the RMDQ.

The correlation coefficient with pain intensity was moderate $(r=0.46)$. Correlations with divergent constructs such as fear avoidance (Tampa Scale of Kinesiophobia) and Pain Catastrophizing Scale were generally lower and ranged from $r=0.22$ to $r=0.37$ (Table 3 ).

Table 2 Results of factor analysis (after oblique rotation) $(\mathrm{N}=180)$

\begin{tabular}{|c|c|c|c|c|c|c|}
\hline \multirow[t]{2}{*}{ Item } & \multirow[t]{2}{*}{ Category } & \multirow[t]{2}{*}{ Communalities } & \multicolumn{4}{|c|}{ Factor loadings $^{a}$} \\
\hline & & & $\mathbf{F I}$ & $\mathbf{F 2}$ & F3 & F4 \\
\hline $\mathrm{I}$ & Get out of bed & 0.63 & 0.52 & -0.10 & & 0.26 \\
\hline 13 & Take something out of a floor cupboard & 0.70 & 0.84 & -0.12 & & \\
\hline 14 & Make your bed & 0.67 & 0.60 & & -0.22 & 0.13 \\
\hline 15 & Put on socks (pantyhose) & 0.66 & 0.79 & & & \\
\hline 16 & Bend over to clean the bathtub & 0.57 & 0.62 & & -0.12 & 0.14 \\
\hline 17 & Move a chair & 0.54 & 0.45 & & 0.41 & \\
\hline 7 & Climb one flight of stairs & 0.59 & 0.21 & 0.49 & 0.18 & \\
\hline 8 & Walk in the neighborhood & 0.95 & & 0.94 & & \\
\hline 9 & Walk several kilometers & 0.62 & & 0.66 & -0.13 & \\
\hline 12 & Run in the neighborhood & 0.34 & 0.19 & 0.24 & -0.21 & \\
\hline 10 & Take something from a high shelf & 0.54 & & & 0.50 & \\
\hline II & Throw a ball & 0.40 & & & 0.42 & \\
\hline 18 & Pull or push heavy doors & 0.74 & & & 0.85 & \\
\hline 19 & Carry two bags of groceries & 0.75 & & -0.13 & 0.82 & \\
\hline 20 & Lift and carry a heavy suitcase & 0.65 & & & 0.74 & \\
\hline 2 & Sleep through the night & 0.44 & & & & 0.57 \\
\hline 3 & Turnover in bed & 0.47 & 0.24 & & & 0.48 \\
\hline 4 & Ride in a car & 0.35 & & 0.14 & -0.14 & 0.50 \\
\hline 5 & Stand up for $20-30$ minutes & 0.37 & & -0.19 & & 0.56 \\
\hline \multirow[t]{4}{*}{6} & Sit in a chair for several hours & 0.49 & & & & 0.71 \\
\hline & Eigenvalue & & 9.16 & 1.60 & 1.18 & 1.10 \\
\hline & Explained variance (\%) & & 43.79 & 6.10 & 4.43 & 3.12 \\
\hline & Cronbach's $\alpha$ & & 0.90 & 0.82 & 0.87 & 0.76 \\
\hline
\end{tabular}

Notes: 'Factor loadings above 0.2 are shown. FI, bending; F2, ambulation; F3, brief effortful movements; F4, long-lasting postures. 


\section{Discussion}

The present study managed to successfully perform the first cross-cultural adaption of one of the most important disability scales (QBPDS) into German. The major goals were the evaluation of its psychometric properties and to provide additional empirical support for the underlying factors.

The German version of the QBPDS showed excellent internal consistency for the full scale. Internal consistency for the four subscales was slightly lower, although in keeping with the results of other studies. ${ }^{18}$ Given that Cronbach's $\alpha$ is dependent upon the number of items, it is not surprising that the subscales showed lower scores. Based on the quality criteria of Terwee et al, ${ }^{26}$ the smallest score of the fourth factor is also still within a good range. The higher the scores the better they could be interpreted also on an individual level. In this aspect, it is not certain whether the fourth scale is reliable enough to allow individual diagnostic additional to group comparisons. Future studies including confirmatory factor analysis could clarify this issue. Convergent validity was confirmed by a high correlation with the PDI. However, the correlation between the QBPDS and the RMDQ was weaker than expected, raising the question of whether the two scales measure the same aspects of functional disability. As reported by the World Health Organization, disability is "a state of decreased functioning associated with disease, which is experienced as an impairment, activity limitation, or participation restriction. ${ }^{" 30}$ According to this definition, the QBPDS solely focuses on the aspect of activity constraints. A comparison of the two questionnaires suggests that the RMDQ uses a broader concept of disability, including items related to avoidance, protection behavior, pain, and appetite.

Divergent validity of the QBPDS can be assumed to be good, with a moderate correlation found with pain intensity suggesting that it measures disability relatively independent of pain. ${ }^{2,18}$ Correlations to other pain-related constructs

Table 3 Construct validity (correlation coefficient)

\begin{tabular}{lllllll}
\hline Measures & QBPDS & PDI & RMDQ & NRS & TSK & PCS \\
\hline QBPDS & $\mathrm{I}$ & $0.78^{* *}$ & $0.54^{* *}$ & $0.46^{* *}$ & $0.22^{*}$ & $0.55^{* *}$ \\
PDI & $0.78^{* *}$ & $\mathrm{I}$ & $0.49^{* *}$ & $0.45^{* *}$ & $0.25^{* *}$ & $0.58^{* *}$ \\
RMDQ & $0.54^{* *}$ & $0.49^{* *}$ & $\mathrm{I}$ & $0.30^{*}$ & $0.38^{* *}$ & $0.43^{* *}$ \\
NRS & $0.46^{* *}$ & $0.49^{* *}$ & $0.28^{* *}$ & $\mathrm{I}$ & $0.18^{*}$ & $0.38^{* *}$ \\
TSK & $0.22^{*}$ & $0.25 * *$ & $0.38^{*}$ & 0.08 & $\mathrm{I}$ & $0.48^{* *}$ \\
PCS & $0.37^{* *}$ & $0.57^{* *}$ & $0.43^{* *}$ & $0.38^{* *}$ & $0.48^{* *}$ & $\mathrm{I}$ \\
\hline
\end{tabular}

Note: Bivariate Pearson's correlation coefficients. $* P<0.05$, $* * P<0.01$. Abbreviations: NRS, Numeric Rating Scale; PCS, Pain Catastrophizing Scale; PDI, Pain Disability Index; QBPDS, Quebec Back Pain Disability Scale; RMDQ, RolandMorris Disability Questionnaire; TSK, Tampa Scale of Kinesiophobia. such as fear avoidance and pain catastrophizing were fair to moderate demonstrating its good discriminating power. A total of $75 \%$ of the results are still in correspondence with the preceding hypotheses so that construct validity can be positively interpreted.

The investigation of the factor structure of the QBPDS was of particular interest, as only two studies aside from the original study by Kopec et al examined the factor structure of this measure and reported heterogeneous results. ${ }^{2,17,18}$ For clinicians, the interpretation of subscales gives more detailed information in comparison to a total score. A high sum score means that the patient is generally disabled in everyday activities but it is not clear which particular activities are impaired and could be practiced during treatment. Furthermore, the subscales indicate the degree of impairment so that the clinician could estimate whether a short or a longer version of treatment is necessary.

In a context of a cultural adaption and validation study where possible cultural differences can emerge, we preferred to first perform an exploratory factor analysis, which tries to find a factor structure in the actual data. Based on the current results, further studies with bigger sample sizes are required to compare the different factor structures with confirmatory factor analysis.

In comparison to former studies, the results of the present study support a four-factor solution, including replicating the original two factors "bending" and "ambulation". In addition, two alternative subscales are suggested: "brief effortful movements" and "long-lasting postures". "Brief effortful movements" includes items assessing impairment in movements (eg, carrying, lifting, and pulling) and handling heavy objects, and "long-lasting postures" mainly includes the former categories "bed/rest" and "sit/stand". Based on patient's reports, the differentiation between long-lasting and short-term activities seems likely to be clinically important. This distinction gives proper instructions to the therapist whose activities could be used for exposure sessions. In addition, other measures such as the Photograph Series of Daily Activities, which assesses the perceived harmfulness of different movements, also differentiate between intermittent load and long-lasting postures. ${ }^{31}$

The four factors explain $57.43 \%$ of the total variance, which is less than in previous studies. One possible explanation for this finding could be differences in the study samples. Compared to other studies, we possibly have a selection bias as many participants showed elevated scores in specific measures of fear avoidance such as the Tampa Scale 
of Kinesiophobia. According to this, it is possible that our sample represents a subgroup of back pain patients. Thus, the generalizability of our findings might be limited. Based on the current results, further studies with bigger sample sizes are required to compare the different factor structures also with confirmatory factor analysis.

Concerning the selection of patients and the evaluation of treatment effects adequate measurements, for example, for pain-related disability are crucial. ${ }^{32}$ In terms of tailored treatment, the QBPDS demonstrates an excellent disability assessment tool for the selection of a subgroup of chronic low back pain patients who are disabled by pain-related fears and avoidance behaviors. Future studies should analyze the predicted value of the QBPDS and its sensitivity to find out patients who benefit most from exposure-based treatments.

\section{Conclusion}

In summary, this psychometric study supports the use of the German version of the QBPDS as a reliable and valid self-report instrument for the assessment of functional disability. Furthermore, the results indicated four underlying dimensions, including two of the original factors ("bending" and "ambulation") and two new subscales, which we labeled "brief effortful movements" and "longlasting postures". We recommend the QBPDS when the assessment of activity limitations is of particular interest, because the items focus solely on constraints in basic daily activities. This may be of particular interest in studies evaluating psychological treatments, especially trials analyzing cognitive behavioral treatments such as graded in vivo exposure, which include engaging in previously avoided daily activities.

\section{Acknowledgment}

This study was funded by a German Research Foundation (Deutsche Forschungsgemeinschaft/DFG) grant G1 607/5-1.

\section{Disclosure}

The authors report no conflicts of interest in this work.

\section{References}

1. Vlaeyen JWS, De Jong J, Geilen M, Heuts P, Van Breukelen G. Graded exposure in vivo in the treatment of pain-related fear: a replicated singlecase experimental design in four patients with chronic low back pain. Behav Res Ther. 2001;39:151-166.

2. Kopec JA, Esdaile JM, Abrahamowicz M, et al. The Quebec Back Pain Disability Scale. Spine (Phila. Pa. 1976). 1995;20(3):341-352.

3. Dworkin RH, Turk DC, Farrar JT, et al. Core outcome measures for chronic pain clinical trials: IMMPACT recommendations. Pain. 2005; 113(1-2):9-19.
4. Costa LOP, Maher CG, Latimer J. Self-report outcome measures for low back pain: searching for international cross-cultural adaptations. Spine (Phila. Pa. 1976). 2007;32(9):1028-1037.

5. Tait RC, Chibnall JT, Krause S. The Pain Disability Index: psychometric properties. Pain. 1990;40(2):171-182.

6. Roland M, Morris R. A study of the natural history of back pain. Spine (Phila. Pa. 1976). 1983;8(2):141-144.

7. Fairbank JC, Davies JB, Couper J, O'Brien JP. The Oswestry Low Back Pain Questionnaire. Physiotherapy. 1980;66:271-273.

8. Smeets R, Köke A, Lin C-W, Ferreira M, Demoulin C. Measures of function in low back pain/disorders: Low Back Pain Rating Scale (LBPRS), Oswestry Disability Index (ODI), Progressive Isoinertial Lifting Evaluation (PILE), Quebec Back Pain Disability Scale (QBPDS), and Roland-Morris Disability Questionnaire. Arthritis Care Res. (Hoboken). 2011;63 Suppl 11(November):S158-S173.

9. Schoppink LE, van Tulder MW, Koes BW, Beurskens SA, de Bie RA. Reliability and validity of the Dutch adaptation of the Quebec Back Pain Disability Scale. Phys Ther. 1996;76(3):268-275.

10. Misterska E, Jankowski R, Glowacki M. Quebec Back Pain Disability Scale, Low Back Outcome Score and revised Oswestry low back pain disability scale for patients with low back pain due to degenerative disc disease: evaluation of Polish versions. Spine (Phila. Pa. 1976). 2011; 36(26):E1722-E1729.

11. Alnahhal A, May S. Validation of the Arabic version of the Quebec Back Pain Disability Scale. Spine (Phila. Pa. 1976). 2012;37(26):E1645-E1650.

12. Rodrigues MF, Michel-Crosato E, Cardoso JR, Traebert J. Psychometric properties and cross-cultural adaptation of the Brazilian Quebec back pain disability scale questionnaire. Spine (Phila. Pa. 1976). 2009;34(13):E459-E464.

13. Melikoglu MA, Kocabas H, Sezer I, Bilgilisoy M, Tuncer T. Validation of the Turkish version of the Quebec back pain disability scale for patients with low back pain. Spine (Phila. Pa. 1976). 2009;34(6): E219-E224.

14. Wei X, Yi H, Wu B, et al. A valid cross-culturally adapted simplified Chinese version of the Quebec Back Pain Disability Scale. J Clin Epidemiol. 2012;65(12):1321-1328.

15. Kopec JA, Esdaile JM, Abrahamowicz M, et al. The Quebec Back Pain Disability Scale: conceptualization and development. J Clin Epidemiol. 1996;49(2):151-161.

16. World Health Organization. International Classification of Impairments, Disabilities and Handicaps - A manual of Classification Relating to the Consequences of Disease. Geneva: World Health Organization; 1980.

17. Christakou A, Andriopoulou M, Asimakopoulos P. Validity and reliability of the Greek version of the Quebec Back Pain Disability Scale. J Back Musculoskelet Rehabil. 2011;24(3):145-154.

18. Valasek T, Varga PP, Szövérfi Z, Kümin M, Fairbank J, Lazary A. Reliability and validity study on the Hungarian versions of the Oswestry Disability Index and the Quebec back pain disability scale. Eur Spine J. 2013;22(5):1010-1018.

19. Beaton DE, Bombardier C, Guillemin F, Ferraz MB. Guidelines for the process of cross-cultural adaptation of self-report measures. Spine (Phila. Pa. 1976). 2000;25(24):3186-3191.

20. Wiesinger GF, Nuhr M, Quittan M, Ebenbichle G, Wölfl G, Fialka-MoserV. Cross-cultural adaptation of the Roland-Morris Questionnaire for German-speaking patients with low back pain. Spine (Phila. Pa. 1976). 1999;24(11):1-7.

21. Dillmann U, Nilges P, Saile H, Gerbershagen HU. Behinderungseinschätzung bei chronischen Schmerzpatienten [Assessment of disability in chronic pain patients]. Schmerz. 1994;8:100-110. German.

22. Rusu AC, Kreddig N, Hallner D, Hülsebusch J, Hasenbring MI. Fear of movement/(Re)injury in low back pain: confirmatory validation of a German version of the Tampa Scale for Kinesiophobia. BMC Musculoskelet Disord. 2014;15:280.

23. Meyer K, Sprott H, Frances A. Cross-cultural adaptation, reliability, and validity of the German version of the Pain Catastrophizing Scale. J Psychosom Res. 2008;64:469-478. 
24. O'Connor BP. SPSS and SAS programs for determining the number of components using parallel analysis and Velicer's MAP test. Behav Res Methods Instrum Comput. 2000;32:396-402.

25. Cronbach LJ. Coefficient alpha and the internal structure of tests. Psychometrika. 1951;16(3):297-334.

26. Terwee CB, Bot SDM, de Boer MR, et al. Quality criteria were proposed for measurement properties of health status questionnaires. J Clin Epidemiol. 2007;60(1):34-42.

27. Fisseni H-J. Lehrbuch zur psychologischen Diagnostik: mit Hinweisen zur Intervention (2., überarbeitete und erweiterte Aufl) [Textbook for psychological diagnostic: with comments for interventions (2nd revised edition)]. Göttingen: Hogrefe-Verlag; 1997. German.

28. Leeuw M, Goossens MEJB, van Breukelen GJP, et al. Exposure in vivo versus operant graded activity in chronic low back pain patients: results of a randomized controlled trial. Pain. 2008;138(1):192-207.
29. Linton SJ, Boersma K, Jansson M, Overmeer T, Lindblom K, Vlaeyen JWS. A randomized controlled trial of exposure in vivo for patients with spinal pain reporting fear of work-related activities. Eur J Pain. 2008;12:722-730.

30. World Health Organization (WHO). ICF: International Classification of Functioning, Disability and Health. Geneva: WHO; 2001.

31. Kugler K, Wijn J, Geilen M, De Jong J, Vlaeyen JWS. The Photograph series of Daily Activities (PHODA). CD-Rom; 1999.

32. Williams ACD, Eccleston C, Morley S. Psychological therapies for the management of chronic pain (excluding headache) in adults. Cochrane Database Syst Rev. 2012;11:CD007407.
Journal of Pain Research

\section{Publish your work in this journal}

The Journal of Pain Research is an international, peer-reviewed, open access, online journal that welcomes laboratory and clinical findings in the fields of pain research and the prevention and management of pain. Original research, reviews, symposium reports, hypothesis formation and commentaries are all considered for publication.

\section{Dovepress}

The manuscript management system is completely online and includes a very quick and fair peer-review system, which is all easy to use. Visit http://www.dovepress.com/testimonials.php to read real quotes from published authors.

\footnotetext{
Submit your manuscript here: http://www.dovepress.com/journal-of-pain-research-journal
} 